\title{
SOME RESULTS FOR THE ZEROS OF A CLASS OF FIBONACCI-TYPE POLYNOMIALS
}

\author{
AMAL AL-SAKET
}

Abstract. In this article, we obtain a rectangle that contains all the zeros of a class of Fibonaccilike polynomials. Then we obtain some relations and majorizations for the real and imaginary parts of the zeros of such polynomials.

Mathematics subject classification (2010): 11B39, 11B37, 15A18, 26C10,15A42, $30 \mathrm{C} 15$. trix.

Keywords and phrases: Fibonacci-like polynomials, zeros of polynomials, eigenvalues, Hermitian ma-

\section{REFERENCES}

[1] F. MÁtYÁs, Bounds for the zeros of Fibonacci-like Polynomials, Acta Acda. Paedagog. Agriensis Sect. Mat., 25 (1998): 15-20.

[2] P. E. RICCI, Generalized Lucas polynomials and Fibinacci polynomials, Riv. Mat. Univ. Parma, 4 (1995): 137-147.

[3] Y. WANG AND M. HE, Zeros of a class of Fibonacci-type polynomials, the Fibonacci quarterly, $\mathbf{4 2 . 4}$ (2004): 341-347.

[4] R. Bhatia, Matrix Analysis, Springer, New York, 1997.

[5] R. A. Horn And C. R. Johnson, Matrix Analysis, Cambridge Univ. Press, Cambridge, 1985.

[6] R. A. Horn And C. R. Johnson, Topics in Matrix Analysis, Cambridge Univ. Press, Cambridge, 1991.

[7] T. Amdeberhan, A note on Fibonacci-type polynomials, Integers 10 (2010), 13-18.

[8] S. HaLICI, On some Fibonacci-type polynomials, Applied Mathematical Sciences, 6, 22 (2012), $1089-1093$. 